\title{
Implications of the CoVID-19 Pandemic
}

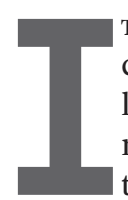
T IS LATE April 2020 as I write this column and it will appear in early June, at which time I expect we may only just be emerging from the "shelter at home" restrictions imposed by the governors of most of the States in the Union. I contracted the disease in mid-March and spent about three weeks recovering. While my symptoms were mild, the virus left me low on energy and it took time to get back to normal levels. It could have been much worse, and it is for many people, some of whom do not survive. I had occasion to think and speculate about what our profession has to contribute in the response to this worldwide pandemic.

Computing has a lot to offer, not least is what I will call "computational- $x$ " for many values of " $x$." Biology, astronomy, physics, linguistics, chemistry, and cosmology are all changed and in some ways enhanced by the prefix. With sufficient computing power and the use of new tools such as machine learning (ML) for deep, multilayer neural networks, we are able to analyze data effectively in ways not feasible earlier. I read one report that ML helped to identify a small number of molecules that might interfere with a virus' ability to "dock" with a cell and inject its RNA or DNA to take over the cell's genetic machinery and reproduce the virus. The search space had billions of possible small molecules. $^{\text {a }}$ There are many reports from sources around the world that are making use of supercomputing capacity, neural networks, specialized processing (such as Graphical Processing Units and Google's Tensor Flow processors)

a https:/www.genengnews.com/insights/ trends-for-2020/artificial-intelligence-is-helping-biotech-get-real/ and text analysis using ML to uncover possible responses to the novel SARSCOV-2 virus.

As a member of the U.S. Department of Energy's Advanced Scientific Computing Advisory Committee, I was privileged to listen to many reports of discoveries related to the pandemic that illustrated for me that we are only just beginning to take advantage of new algorithms and large-scale data analytics to shed light on difficult and complex problems, not the least of which are the mysteries and complexities of bio-eco-system interactions. The SARS-COV-2 virus appears to have originated in bats (as have several other corona viruses) but reached humans through other intermediary hosts. Since this virus is RNA-based, it has a higher likelihood of mutation simply because the RNA replication process is less stable than the counterpart for DNA. Mutation can frustrate the intent of a vaccine that might be based in part on particular aspects of the virus, such as the docking spicule used by the virus to bind to a cell receptor in

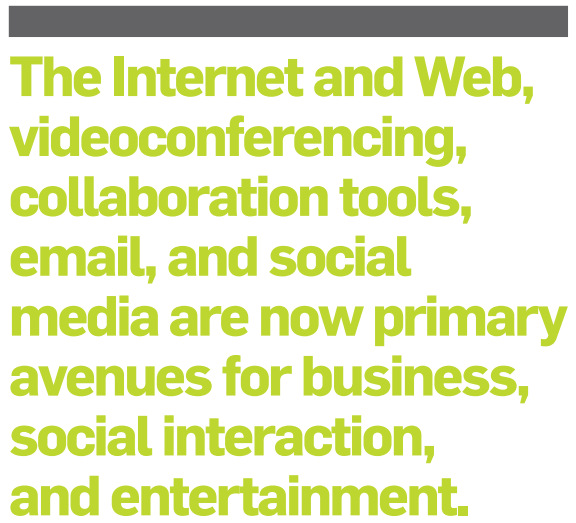
and entertainment. preparation for injecting its RNA payload into a victim cell.

Turning to our global response to the pandemic introduced by COVID-19, it has become apparent that so-called social distancing has been an important element of response that is intended to limit the spread of the airborne disease. Wearing masks to keep from spreading the virus, washing hands frequently, avoiding touching the face, eyes, nose and mouth, staying six feet or more apart, banning group gatherings that would trigger superspreading of the disease, shutting down restaurants, sports events, movie theaters, personal service businesses (such as hair salons, counter services at banks) and other activities that would contribute to viral spread has been helpful medically but disastrous from an economic perspective. The Internet and World Wide Web, videoconferencing, collaboration tools, email, and social media are now primary avenues for business, social interaction, and entertainment. It is astonishing the system has been able to absorb so much new demand but indicative of the capacity investments made in part to support streaming video.

I wonder what aspects of our daily working lives will be permanently altered, post-COVID-19. Will we no longer shake hands? Will the travel, hotel, and restaurant businesses be permanently altered? Will working and schooling from home become more common and even preferred? There is no doubt in my mind that our profession and the products it creates will have a prominent role in shaping our post-COVID-19 society. That's an awesome responsibility!

Vinton G. Cerf is vice president and Chief Internet Evangelist at Google. He served as ACM president from 2012-2014.

Copyright held by author 